Univerzitet u Novom Sadu, Asocijacija centara za interdisciplinarne i multidisciplinarne studije $\mathrm{i}$ istraživanja,

Novi Sad

DOI 10.5937/kultura1234325V

UDK 316.647.5:2(497.11)

316.74:2(497.11)

pregledni rad

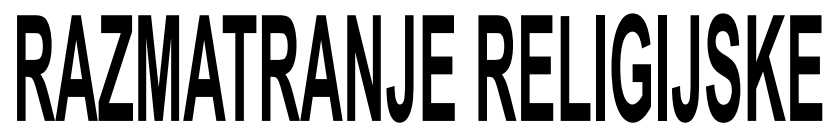
TOLERANCIJEU

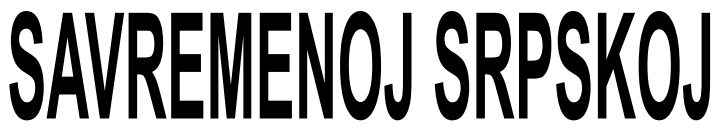
FILOZOFSKOJI DRUSTVENOJ MISLI

Sažetak: Nakon raspada SFRJ $i$ u svetlu novih društvenih okolnosti, religijske zajednice imaju nov društveni status i novu društvenu ulogu; one su izašle iz privatne i našle svoje mesto u javnoj sferi. U kontekstu desekularizacije društvenog života, religijska tolerancija ima veći značaj, kako za same religijske zajednice, tako i za druge društvene aktere $i$ društvo u celini. Imajući to u vidu, cilj ovog rada je da analizira teorijska stanovišta i određenja pojma religijske tolerancije u radovima domaćih autora - kako filozofa i predstavnika društvenih nauka, tako $i$ teologa. Osim analize uticaja društvenog konteksta, analiziraće se teza o relaciji između monoteizma i netolerancije, a u razmatranje će se uzeti i doktrinarni aspekt, odnosno sadržaj svetih spisa. Posvetiće se pažnja i tome ko su mogući subjekti religijske tolerancije, ukazati na problem paternalizma u govoru o religiji i religijskom, te istaći važnost međusobnog uvažavanja i poštovanja između aktera u dijaloškoj komunikaciji. U vezi sa prisutnim stavovima o nemogućnosti tolerancije između različitih konfesija, odnosno religija, budući da na različit način gledaju na put čovekovog spasenja, podvući će se razlika između vrednovanja saznanja $i$ vrednovanja aktera - pojedinaca, zajednica $i$ društvenih grupa. 


\section{SLOBODAN VASIĆ}

Ključne reči: religijska tolerancija, društveni kontekst, sveti spisi, paternalizam, monoteizam, doktrina

\section{Uvod}

U istoriji zapadne civilizacije, religijska tolerancija je posledica dva društveno-istorijska procesa: reformacije i uspona građanstva. Moderno uobličavanje pojma tolerancije i prvi ozbiljniji doprinos razumevanju ove pojave, delo je engleskog filozofa Džona Loka (John Locke). ${ }^{1}$ Međutim, u našim uslovima, religijska tolerancija ima drugačije istorijske motive i društvene posledice u različitim društveno-istorijskim kontekstima. U periodu socijalizma, uloga religije i crkve u društvu bila je definisana sadržajem komunističke i antinacionalističke platforme. Raspadom zajedničke države, do koje dolazi nakon eskalacije društvene, ekonomske i političke krize, dolazi do smene do tada opšteprihvaćenih vrednosti, a njihovo mesto zauzimaju revitalizovane tradicionalne vrednosti $\mathrm{i}$ tradicionalni identiteti. Pa tako, nakon vremena potiskivanja, na društvenom značaju ponovo dobijaju religijske vrednosti i konfesionalne identifikacije.

Imajuću u vidu da u društvenom kontekstu desekularizacije, religijska tolerancija ima veći društveni značaj, u ovom radu pažnju ćemo posvetiti analizi teorijskih stanovišta pojma religijske tolerancije u radovima domaćih autora - kako filozofa i predstavnika društvenih nauka, tako i teologa. Budući da su na evropskom prostoru, pa tako i u našim uslovima, dominantne monoteističke religije, najpre ćemo analizirati vezu između monoteizma i tolerancije.

\section{Monoteizam i ne-tolerancija}

U radu pod naslovom Monoteizam $i$ (ne)tolerancija, Dragan Jakovljević kritički se osvrnuo na stavove Đure Šušnjića iznetim u dvotomnoj knjizi Religija: „Hrišćanstvo duguje svoje prodore u svest i podsvest verničkih masa netrpeljivosti prema drugim veroispovestima. Vera u jednog Boga prosto zahteva netrpeljivost i isključivost: ako postoji samo jedan Bog, onda on ne trpi druge bogove“2. U pogledu toga, Šušnjić se poziva na istorijski period u kome je hrišćanstvo postalo zvaničnom religijom Rimskog carstva. ${ }^{3}$

1 O teorijskim pristupima religijskoj toleranciji videti: Vasić S., Teorijski pristupi religijskoj toleranciji, Kultura br. 129, Beograd 2010, str. 349-368.

2 Šušnjić Đ., Religija II, Beograd 1994, str. 334.

3 Jakovljević D., Monoteizam i (ne)tolerancija, Teme br. 1-2, Niš 2005, str. 176. 


\section{SLOBODAN VASIĆ}

Jakovljević takvo određenje smatra generalizacijom, budući da „do rasprostranjavanja hrišćanstva faktički nije došlo tek sa njegovim proglašenjem za državnu religiju, već znatno ranije, i to upravo u periodu u kojem ono ne samo da nije imalo takav status, već su, naprotiv, njegovi pobornici i apostoli bili izlagani brutalnim proganjanjima i teroru, te su svoje verske obrede često morali praktikovati u svojevrsnoj ilegali““4. Ukazujući na ovaj izvorni put širenja hrišćanstva, Jakovljević dodaje da ono što se desilo sa hrišćanstvom posle proglašavanja za državnu religiju, ne predstavlja otpočinjanje prodora već naprotiv „oslobađanje (od sapinjućeg dejstva institucionalnih barijera) njegovih već ranije iskazanih potencijala uticaja na „mase“, tj. šire društvene slojeve..." ${ }^{\text {"5 }}$ Zapravo, širenje hrišćanstva putem potiskivanja, nije istorijski sveobuhvatno i sveprisutno, te je empirijski neodrživo redukovati ga na taj modus. ${ }^{6} \mathrm{U}$ mnogim društvima hrišćanstvo nije uzdizano u status državne religije, te se prilikom analiziranja uzroka širenja hrišćanstva moraju uzeti u obzir i drugi argumenti, poput privlačnosti doktrine, delatnosti misionara, uspesi u artikulisanju duhovne dimenzije života i sl. ${ }^{7} \mathrm{U}$ tom smislu jednoznačna korelacija između monoteizma sa jedne, i netrpeljivosti sa druge strane, pokazuje se kao problematična.

Iskaz: „Vera u jednog Boga prosto zahteva netrpeljivost i isključivost: ako postoji samo jedan Bog, onda on ne trpi druge bogove“, može se analizirati i na pojmovnom nivou. Jakovljević smatra da ako se tvrdi da postoji božanstvo i da je ono numerički jedno, „time uopšte nije rečeno ujedno i to da ne treba priznati pravo na postojanje alternativnim teističkim hipotezama i na njima izgrađenim religijskim sistemima, odnosno da se prema njihovim pojavljivanjima i zastupnicima mora ili treba praktikovati netrpeljivost!“"8 $\mathrm{S}$ jednakim pravom može se tvrditi da ,ako postoji $1+\mathrm{n}$ bogova, onda oni ne trpe druge (i drugačije) bogove“. On zaključuje da nije sama numerička vrednost o egzistenciji Boga/bogova, ona koja je odlučujuća za stav ne/tolerancije, već teza o jedinosti (a ne jednosti), odnosno ključno je insistiranje na ekskluzivnosti važenja datih ontoloških pretpostavki. ${ }^{9} \mathrm{U}$ tom smislu ekskluzivizam ontoloških pretpostavki može u podjednakoj meri biti primenjen, kako na monoteizmu tako i na politeizmu, jer ,ni politeizam ne podrazumeva nikakvu anarhiju u pogledu

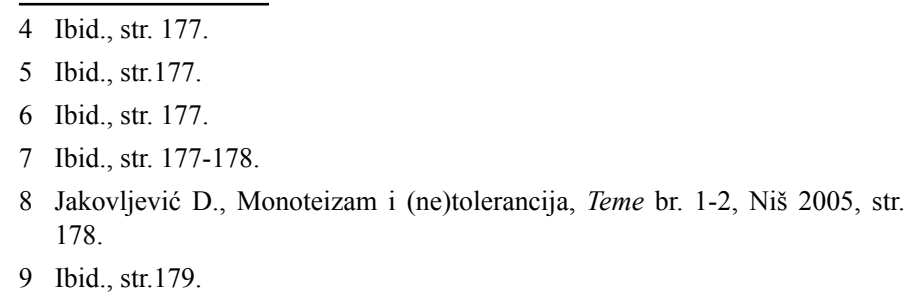


pitanja koliko i kakvih božanstava zapravo postoji“"10. Pored toga, svaki politeizam predviđa postojanje sasvim određenog broja bogova, sa specifičnim svojstvima i prirodom. ${ }^{11}$

Za zagovaranje verske (ne)trpeljivosti, ključno je dakle pitanje odnosa prema alternativnim, nevažećim religijskim tezama. Uz tvrdnju da postoji jedan, dva ili bilo koji drugi broj bogova, sasvim je moguće zauzeti, na primer, sledeći stav: „Prema aternativnim (neispravnim) religijskim shvatanjima, kojima se predviđa postojanje nekog sasvim drugog i drugačijeg Božanstva, odnosno različitog broja bogova i zastupnicima tih shvatanja, treba praktikovati trpeljivost, uzdržavati se od bilo kakvih omalovažavanja, a naročito od pritisaka ili čak diskriminacije i proganjanja inovernih u bilo kom obliku“12.

U tom smislu ,nije sprovodljivo logičko podvajanje između bazičnih pretpostavki politeizma i monoteizma u relaciji prema potencijalnoj verskoj netrpeljivosti““13.

Jakovljević naglašava da bi trebalo napraviti razliku između monoteizma, kao ontološke teze, i skupa različitih doktrinarnih pretpostavki, sa kojima on biva ukomponovan u sklopu određenih religijskih sistema. Potom, trebalo bi utvrditi kakve stavove o netoleranciji sadrže sami sveti spisi, kakav je sadržaj teoloških interpretacija (ko je od teologa zastupao toleranciju, a ko netoleranciju), koji su zvanični crkveni stavovi po tom pitanju, te da bi trebalo uzeti u obzir i okolnost da je od novovekovnog perioda unutar hrišćanstva sve izraženija tendencija ka stanovištu konfesionalne trpeljivosti. ${ }^{14}$

\section{Određenja (religijske) tolerancije}

U knjizi Dijalog i tolerancija, Đuro Šušnjić ističe da ideja o toleranciji počiva na tri pretpostavke: 1) ontološka pretpostavka o nedovršenosti ljudskog bića, 2) gnoseološka pretpostavka o ograničenosti čovekove spoznaje i 3) aksiološka pretpostavka o relativizmu grupnih vrednosti. ${ }^{15}$ Šušnjić smatra da je trpeljivost „uslov razvoja, kao što je kiseonik uslov disanja. Ako ideju trpeljivosti jedno društvo nije ugradilo u karakter svojih članova,

10 Ibid., str. 179.

11 Ibid., str. 180.

12 Ibid., str. 181.

13 Jakovljević D., Monoteizam i (ne)tolerancija, Teme br. 1-2, Niš 2005, str. 181.

14 Jakovljević D., Monoteizam i (ne)tolerancija, Teme br. 1-2, Niš 2005, str. 185-187.

15 Šušnjić Đ., Dijalog i tolerancija, Beograd 1997, str. 204. 


\section{SLOBODAN VASIĆ}

onda ono nema budućnosti“"16. Jer ,sve što u kulturi postoji rođeno je susretom različitih ideja“"17. Prema njegovom mišljenu, danas su na ceni razlike, a ne sličnosti. Kada se sličnostima poklanja pažnja, to se čini ne da bi im se istakla vrednost, već da bi im se ona osporila. ${ }^{18}$ Ali traženje bitno zajedničkih (a ne samo zajedničkih, jer ono što je zajedničko ne mora uvek biti bitno) osobina tako različitih religija (uporedna metoda) nije motivisano samo teorijskom potrebom njihovog boljeg upoznavanja, nego i željom da se izgrade mostovi među njima, tako potrebni u ovom vremenu netrpeljivih. ${ }^{19}$

Trpeljivost ne predstavlja ravnodušnost, koja ima takav kvalitet da pokazuje spremnost da se drugi prizna, ali da se prema njemu ne pokazuje nikakav interes. Trpeljiv je naprotiv svaki čovek koji ima želju da sasluša drugoga i volju da ga razume. U tom smislu trpeljivost je ,svest da više ograničenih gledišta pružaju mogućnost za stvaranje širih i dubljih stanovišta“20. Čudna stvar u vezi sa trpeljivošću, nastavlja Šušnjić, jeste to da trpeljivi mogu biti samo oni koji imaju duboka uverenja, ,jer se njihovo uverenje odmerava u odnosu na druga sa kojima se ne slaže“"21.

Tolerancija se može posmatrati na dva nivoa: na nivou ubeđenja, dakle kao trpeljivost prema ubeđenjima drugoga, i na delatnom nivou, kao trpeljivost prema postupcima drugoga. Ova dva nivoa su različita, ali imaju unutrašnju vezu, jer „misao i čin nisu isto, iako misao ima težnju da se produži u čin"22. U tom smislu, Šušnjić smatra da se valja ,zalagati za neograničenu trpeljivost prema izražavanju mišljenja i za ograničenu trpeljivost prema nekim vrstama ponašanja“"23. To je paradoks tolerancije, jer ako se tolerancija dosledno sprovede, trebalo bi biti trpeljiv i prema onima koji su netrpeljivi. „Trpeljivost kao norma je nešto apsolutno i nadiskustveno, a trpeljivost kao odnos nešto relativno i iskustveno: stvar mere." ${ }^{24}$

Prema Draganu Jakovljeviću, pod tolerancijom valja razumeti specifičan stav jednih individua ili grupa ljudi prema shvatanjima i načinima ponašanja drugih individua, odnosno grupa, koji može

16 Ibid., str. 211.

17 Ibid., str. 202.

18 Ibid., str. 197.

19 Ibid., str. 219-220.

20 Šušnjić Đ., Dijalog i tolerancija, Beograd 1997, str. 200.

21 Ibid., str. 200.

22 Ibid., str. 217.

23 Ibid., str. 215.

24 Ibid., str. 201. 
biti izražen kroz odgovarajuće postupanje ili kroz izostavljanje određene vrste postupaka, pri čemu važi:

a) Postoje bitne razlike između shvatanja i načina ponašanja jednih i drugih;

b) Razlike se tiču za obe strane značajnih, važnih pitanja;

c) I jedna i druga strana podnose te različitosti, ne preduzimajući postupke diskriminacije, vršenja presija u pravcu napuštanja dotadašnjih shvatanja i načina ponašanja ili čak otvorenog proganjanja i terora $^{25}$.

Ove tri stavke su neophodne da bi se moglo govoriti o pasivnoj toleranciji, dok je za govor o aktivnoj toleranciji potrebno dodati uslov da „obe strane javno i iskreno pokazuju priznavanje i poštovanje postojećih razlika uz spremnost na dijalog, imaju pozitivan odnos prema njihovom ispoljavanju, održavanju i daljem razvoju i tome pružaju podršku u društvenoj praksi. ${ }^{.26}$ Poseban pojam konfesionalne tolerancije se dobija ako u početnom uslovu (a) shvatanja i načine ponašanja, u vezi sa kojima se ispoljavaju bitne razlike, specifikujemo kao religijska shvatanja i sa njima povezanih načina ponašanja vernika, konfesionalnih grupa i zajednica. ${ }^{27}$

Aleksandar Prnjat religijsku toleranciju određuje kao „suzdržavanje od agresivnog reagovanja prema pojavama iz domena religijskog, koje nas iritiraju zbog svoje različitosti u odnosu na naša sopstvena uverenja o religijskim stvarima“28. Pojave iz domena religijskog mogu biti religijska verovanja, religijske radnje i subjekti tih religijskih verovanja i radnji. Prnjat navodi i gradaciju nužnih uslova religijske tolerancije: a) da imamo barem neka relativno čvrsta i stabilna religijska verovanja; b) da smo upoznati sa postojanjem drugih religijskih verovanja; c) da procenjujemo da se naša i ta drugačija religijska verovanja međusobno isključuju; d) da nas ta različitost i procenjena međusobna isključivost ovih verovanja iritiraju i navode na agresivno reagovanje; e) da imamo moć da bez štetnih posledica po nas uđemo u obračun sa datom pojavom. ${ }^{29}$ Za nekoga bi se moglo reći da je religijski tolerantan tek

25 Jakovljević D., Verske razlike i tolerancija, Sociološki pregled br. 4, Beograd 2007, str. 522.

26 Ibid., str. 523.

27 Ibid., str. 523.

28 Prnjat A., Koncept religijske tolerancije. Književnost 10/99, Beograd 1999, str. 1743.

29 Ibid., str. 1743. 


\section{SLOBODAN VASIĆ}

ukoliko se, i pored toga što su svi navedeni uslovi zadovoljeni, suzdržava od agresivnog reagovanja. ${ }^{30}$

Odgovarajući na pitanje kakav stav bi trebalo da zauzme verujući čovek, ukoliko pored sebe ima fanatičnog sagovornika, Vladeta Jerotić smatra da istinski verujući čovek - pravoslavni vernik, „ne treba, zbilja, da ostane mlak i da u ime neke više čovečnosti ili apstraktne religijske univerzalnosti prihvati stav nekog svog, u bitnim pitanjima vere, suprotno uverenog protivnika“31. Podsećajući na reči Nikolaja Berđajeva da „za fanatika ne postoji raznolikost sveta“, te da je revnost ispravnog pravoslavnog čoveka rad na preobražavanju sebe, a fanatizovanog drugih, Jerotić tvrdi da pravi hrišćanin osuđuje fanatizam kao greh, ali ne i fanatičnog čoveka kao grešnika. ${ }^{32}$

On u tekstu Duhovnost i tolerancija razlikuje dva modusa religijske tolerancije: toleranciju između pojedinačnih lica i toleranciju između dva naroda različitih veroispovesti jedinstvene hrišćanske religije. Vladeta Jerotić smatra da čovek nije prirodno tolerantan, te da je strah i odbijanje da se prihvati drukčije ili različito biološke prirode.$^{33}$ Međutim, ,ako je opšte prihvaćena istina da je hrišćanstvo borba za ličnost, jer je „ličnost osnovnija nego biće“ i ako je ličnost čoveku zadata, onda je prirodno da se čovek u toku života menja ,uzrastajući“ i to u prvom redu preko dijaloga s osobama koje zastupaju drugačiji pogled od našeg “"34.

U radu pod naslovom Pravoslavlje $i$ verska tolerancija, stanovište pravoslavnog teologa Radovana Bigovića sadrži određenu dozu skepticizma prema samom pojmu religijske tolerancije ili barem prema samom terminu tolerancija. Naime kako je pojam religijske tolerancije stvorila liberalna pravna i politička filozofija, teolozi radije govore o ekumenizmu i dijalogu. ${ }^{35}$ Bigović navodi primere zbog kojih je pravoslavna crkva skeptična prema tom pojmu:

1) verska tolerancija je često izraz malodušnosti i mlakosti prema istini;

2) ona se često svodi na nivo religijske i crkvene diplomatije i taktike;

30 Ibid., str. 1744.

31 Jerotić V., Duhovnost i tolerancija, Kultura br. 91-92, Beograd 1993, str. 56.

32 Ibid., str. 58.

33 Ibid., str. 59.

34 Ibid., str. 54-55.

35 Bigović R., Pravoslavlje i verska tolerancija, Kultura br. 91-92, Beograd 1993, str. 117. 


\section{SLOBODAN VASIĆ}

3) može sadržati pokušaj sinkretizma, religiozne unifikacije i stapanja svih religija u jednu;

4) ona može biti u funkciji prilagođavanja crkvenih institucija svetovnim, koje mogu da služe ostvarivanju ciljeva potrošačke ideologije. ${ }^{36}$

U tom smislu, tolerancija se ne može svesti na moralno poboljšanje odnosa među brojnim religijama, konfesijama i njihovim institucijama, ,oni treba da budu u funkciji spasenja sveta i čoveka...“" ${ }^{37}$ Nedovoljnost tolerancije Bigović vidi u tome što „nama pravoslavnima nema spasenja ako ne činimo sve što možemo da se spasu i imaju život večni drugi““38. Potrebno je naime „da izađemo iz sebe, da se saživimo sa ne-ja, s drugim ljudima i narodima, koji pripadaju drugim religijama i hrišćanskim konfesijama“"39. Kao preduslov za uspostavljanje uspešnog dijaloga s drugima, Bigović ističe neophodnost uspostavljanja istinskog dijaloga unutar pravoslavnih ljudi. U tom smislu, kao negativne pojave navodi etnofiletizam i etnocentrizam, pojave ,pravedničke arogantnosti“, kompleks superiornosti, zabludu o „nevinom“ Istoku i ,trulom“ Zapadu. ${ }^{40}$ Kao protivteža ovakvim pojavama, može poslužiti činjenica da je čovek društveno biće ili, kako to Bigović kaže, „biće odnosa, biće zajednice“, te da su dijalog i misija sama priroda crkve. ${ }^{41}$

Da bi pripadnici pravoslavnih crkava mogli uspostaviti uspešan dijalog sa drugim hrišćanskim konfesijama, potrebno je poznavati njihove teologije: rimokatoličku, protestantsku, anglikansku, a još teži je problem uspostavljanje dijaloga s nehrišćanskim religijama. Za njegovo uspostavljanje, potrebno je odgovoriti na pitanje šta je u tim religijama što bi trebalo pozitivno da se vrednuje. ${ }^{42}$

$\mathrm{Na}$ empirijskoj ravni, ukoliko pratimo stavove religijskih zajednica u određenom vremenskom periodu, u odnosu na ona pitanja i društvene probleme kojima religijske zajednice posvećuju najveću pažnju, možemo steći približnu sliku o oblicima religijske tolerancije posmatranih religijskih zajednica. ${ }^{43}$ Sociološki

\footnotetext{
36 Ibid., str. 118.

37 Ibid., str. 118.

38 Ibid., str. 119.

39 Ibid., str. 119-120.

40 Bigović R., Pravoslavlje i verska tolerancija, Kultura br. 91-92, Beograd 1993, str. 122.

41 Ibid., str. 123.

42 Ibid., str. 122.

43 U listu srpske patrijaršije Pravoslavlje, u posmatranom periodu 2002-2008, razlikujemo sledeće oblike religijske tolerancije: ratovi i raspad SFRJ, odnos prema društvu, međureligijska tolerancija, odnos prema modernizaciji i čisto
} 


\section{SLOBODAN VASIĆ}

rečeno, religijska tolerancija pri različitim društvenim uslovima ispoljava različita svojstva. Na taj način, različite oblike netolerancije (uostalom, kao i tolerancije) možemo dovesti u vezu sa određenim društveno-političkim uslovima: u našim uslovima, religijska netolerancija raste u kontekstu ratnog okruženja i raspada SFRJ.

U uslove potencijalnog generisanja ne-tolerancije Jakovljević navodi:

1) šira kulturna i politička tradicija, u okviru čega spada i geografska rasprostranjenost određenih religija, kao i prisustvo i širina kontakta s drugim, alternativnim konfesijama;

2) osobenosti konkretnog socijalno-istorijskog miljeau kojemneki religijski sistemi deluju, specifičnosti datog društveno poretka i aktuelnih ekonomskopolitičkih odnosa;

3) realna politika crkvenog establišmenta prema inovernima, koja biva prihvaćena od strane većine vernika. $U$ tom smislu je važna okolnost da li se dati religijski sistem od strane vernika, zastupa fundamentalistički, što je pogodna osnova za razbuktavanje netrpeljivosti;

4) sadržaj samih svetih spisa određene religije. Da li u njemu ima mesta koja bi mogla pružiti opravdanje za konfesionalnu netoleranciju? ${ }^{44}$

Jakovljević na osnovu gore navedenog zaključuje da na karakteristike religijske tolerancije deluje čitav splet činilaca, te da oni nisu istovetnog karaktera, već deluju na različite načine i sa različitom efektivnošću. Netolerantno ponašanje pripadnika jednih konfesija prema pripadnicima drugih konfesija, može se izraziti

kao rezultanta delovanja takvih višestrukih činilaca. ${ }^{45}$

\section{Subjekti tolerancije i dijaloga i njihov međusobni odnos}

Podsticanje istinskog poštovanja različitosti i ravnopravnosti u društvu i poštovanje ljudskih prava, trebalo bi da budu neke od

religijske poruke. O ovoj temi više u: Vasić S., Društveno-politička determinisanost oblika religijske tolerancije - analiza sadržaja religijske štampe $u$ Vojvodini, master rad, Filozofski fakultet, Univerzitet u Novom Sadu, Novi Sad 2010.

44 Jakovljević D., Verske razlike i tolerancija, Sociološki pregled br. 4, Beograd 2007, str. 523-525.

45 Ibid., str. 525. 


\section{SLOBODAN VASIĆ}

osnovnih vrednosti demokratskog društva. Da bi pružili skroman doprinos u tom smeru, ukazaćemo na ograničenja koja proizlaze, sa jedne strane, iz paternalističkog odnosa prema crkvi, odnosno vernicima i religijskoj sferi društva uopšte i, sa druge strane, stava da ateisti, odnosno neduhovni pojedinci ne mogu biti subjekti tolerantnog ponašanja.

Problem paternalizma, odnosno prema formulaciji Aleksandra Prnjata ,jezičko-ekspresivnog paternalizma“, jedna je od tema u polemici koja se razvila između njega i Mihaila Markovića. Prema mišljenju Markovića, „crkva nudi iluzorno zadovoljenje duboke ljudske čežnje za duhovnim vrednostima, za osmišljavanjem individualne egzistencije, za toplim ljudskim odnosima u zajednici lišenoj egoizma i utilitarizma“"46. Ovakvo tvrđenje moglo bi biti dosta problematično, „naime, u njemu se pretpostavlja da ljudi ne mogu sami da procene da li je zadovoljenje njihove čežnje za duhovnim vrednostima i osmišljavanjem individualne egzistencije samo „iluzorno“ ili stvarno" ${ }^{\text {"47 }}$. U tekstu Crkva i paternalizam, Prnjat tvrdi da stav profesora Markovića pripada jednoj vrsti paternalizma, koja bi se mogla označiti kao jezičko-ekspresivna. ${ }^{48}$ Prnjat smatra da bi prilikom iznošenja filozofskih stavova ili tvrdnji trebalo sagledati kategorički ton kojim se te tvrdnje izriču, te da bi na pojedinim mestima bilo umesno uneti izvesne ograde. ${ }^{49}$ Kada je reč o eshatološkim stvarima, bilo bi poželjno da osoba koja nešto izriče upozori da je reč o njenom verovanju ili o verovanju grupe sa kojom se identifikuje. ${ }^{50}$

Sa druge strane, razmatrajući relaciju između duhovnosti i tolerancije, Vladeta Jerotić stoji na stanovištu da istinska duhovnost ide uporedo sa tolerancijom. U vezi sa tim, Jerotić predočava tri moguće teze:

1) čovek nije ni duhovan ni tolerantan;

2) čovek je duhovan, ali nije tolerantan;

46 Marković M., Sloboda i praksa, Beograd 1997, str. 227.

47 Prnjat A., Zapis o crkvi, Književnost br. 7-8-9, Beograd 2000, str. 1120-1121.

48 Prnjat pravi distinkciju između dve vrste paternalizma: jedne koja neposredno proizvodi ograničenje slobode i druge koja to ne čini. Primer za prvu vrstu je zakon, a primer za drugu je komentar. Stavovi profesora Markovića, smatra Prnjat, pripadaju ovoj drugoj vrsti paternalističkog diskursa, te predlaže da bi ona mogla da se nazove jezičko-ekspresivnim paternalizmom. Ovim terminom mogu se označiti isključivo ona jezička izražavanja paternalističkog odnosa koja ne idu dalje od komentara, opaske, saveta itd. O ovoj temi više u: Prnjat A., Crkva i paternalizam, Filozofija i društvo br. 2, Beograd 2008.

49 Prnjat A., O jezičko-ekspresivnom paternalizmu: replika Mihailu Markoviću, Filozofija i društvo br. 3, Beograd 2009, str. 248.

50 Ibid., str. 249. 


\section{SLOBODAN VASIĆ}

3) čovek je duhovan i tolerantan..$^{51}$

Smatramo da ovim tezama ipak nedostaje još jedna, naime ona prema kojoj pojedinac nije duhovan, ali je tolerantan. U tom smislu, modaliteti religijskog dijaloga, kao aktivne forme religijske tolerancije mogu biti sledeći:

1) dijalog između samih religijskih zajednica;

2) dijalog između religijskih zajednica i društva, odnosno države;

3) dijalog koji pored vernika, predstavnika religijskih zajednica i društva, uključuje ateiste i agnostike.

\section{Doktrinarni aspekt tolerancije - sadržaj hrišćanskih svetih spisa}

U pogledu odnosa prema inovernima i jereticima, u hrišćanstvu je karakterističan ambivalentan stav: ističe se kako sloboda prihvatanja određene vere tako i potreba pasivno-trpeljivog odnosa prema pripadnicima drugih konfesija i jereticima. S druge strane, na nekim mestima se afirmišu (Druga saborna poslanica sv. apostola Petra) njihova osuda, sankcionisanje i prokletstvo na propast. ${ }^{52}$

Međutim, pored držanja na distanci kao oblika odnosa prema pripadnicima drugih veroispovesti ${ }^{53}$, Jakovljević navodi još tri stava koja se mogu naći u hrišćanskim spisima, a koja se bitno razlikuju od netolerantnosti:

1) stav ignorisanja $\mathrm{i}$ indiferentnosti u odnosu na jeretike (Titu poslanica sv. apostola Pavla: 3: 10-11);

2) stav strpljivosti i blagosti (Timotiju poslanica druga svetog apostola Pavla: 2: 24-25);

3) stav skromnosti u pogledu posedovanja religijske istine (Sveto jevanđelje po Mateju: 13: 24-30) $)^{54}$.

51 Jerotić V., Duhovnost i tolerancija, Kultura br. 91-92, Beograd 1993, str. 5859.

52 Jakovljević D., Verske razlike i tolerancija, Sociološki pregled br. 4, Beograd 2007, str. 529-530.

53 Jakovljević navodi Fajhtlbauera (Feichtlbauer), koji ističe preporuku uzdržanosti prisutnu u Rimljanima poslanici sv. apostola Pavla, (16:17), kojom se zagovara držanje na distanci od zabludelih jeretika. O ovoj temi više u: Feichtlbauer H., Macht, Religion, Sinn. Macht Religion Sinn?, in: Macht, Religion, Sinn, Eine BAWAG-Anthologie uber Gott und die Welt, Wien, str. 38.

54 Jakovljević D., Verske razlike i tolerancija, Sociološki pregled br. 4, Beograd 2007, str. 530 . 


\section{SLOBODAN VASIĆ}

Međutim, u Novom zavetu su prisutni i takvi stavovi kojima se zagovara netolerancija, odnosno negativniji i agresivniji stav, te se razlike u konfesionalnim shvatanjima stavljaju u rang krivice i moralne propalosti. ${ }^{55}$ Potom, segment hrišćanske doktrine koji operiše predstavom o ,spasonosnoj veri“, sadrži klicu i može pružiti podesnu osnovu za zagovaranje prakse konfesionalne netrpeljivosti, „premda sama njegova formulacija ne uključuje i to zagovaranje“

(Prva saborna poslanica sv. apostola Petrova). ${ }^{56}$

Jakovljević navodi i ona mesta u svetim spisima u kojima se vrlo jasno zagovara i čak zahteva verska trpeljivost: Dela svetih apostola: 5, 29-42; Sveto jevanđelje po Luki: 6, 27; 36-37; Sveto jevanđelje po Mateju: 5, 40-41; Matej: 5, 43-44; Matej: 7, 1-2. ${ }^{57}$

U hrišćanskim spisima, potom, prisutnije je zagovaranje tolerancije prema vankonfesionalnoj sferi, a manje u sferi konfesionalnih razmimoilaženja. Služeći se perspektivom sociologije organizacija, Jakovljević objašnjenje pronalazi u činjenici da su takva odgovarajuća mesta u Novom zavetu bila zapisana u vremenu osvita nove religije, te da je u toj fazi za uspešno formiranje konfesionalne zajednice kao organizovanog pokreta, teško bilo dopustivo bitnije raslojavanje i osipanje. „To bi, naime, značilo prihvatanje vrlo realnog rizika da do njenog uspešnog stasavanja uopšte ni ne dođe..." ${ }^{\text {‘58 }}$

Može se reći da „u hrišćanskim svetim spisima nije dakle prisutan jedan jedinstveni stav, već naprotiv čitav spektar stavova prema verskim razlikama“c59.

\section{Vrednovanje shvatanja i vrednovanje aktera}

$\mathrm{U}$ tekstu Religious and political toleration in the age of globalization, Jovan Babić konstatuje da je religijska tolerancija prvi pojmovni oblik tolerancije, a ,s obzirom na prirodu religijskih vrednosti (njihovu pretenziju na fundamentalnost) verovatno i najteži i najvažniji oblik tolerancije uopšte“"60. Prema Babiću,

55 Druga saborna poslanica sv. apostola Petra, 2: 12-14; Galatima poslanica 1: 9; Timotiju poslanica prva sv. apostola Pavla, 1: 19-20. Navedeno prema: Verske razlike i tolerancija, Sociološki pregled br. 4, Beograd 2007, str. 532.

56 Ibid., str. 533.

57 Jakovljević D., Monoteizam i (ne)tolerancija, Teme br. 1-2, Niš 2005, str. 183-184.

58 Jakovljević D., Verske razlike i tolerancija, Sociološki pregled br. 4, Beograd 2007, str. 536.

59 Ibid., str. 533.

60 Babić J., Religious and political toleration in the age of globalization, Filozofski godišnjak br. 15, Beograd 2002, str. 93. 


\section{SLOBODAN VASIĆ}

minimum verske tolerancije, potpuno neshvatljiv i nedopustiv sa stanovišta apsolutnosti religijskog principa, neophodan je za bilo kakvu sumnju i mogućnost postavljanja bilo kakvih pitanja; ovo pripuštanje razlika je nešto bez čega je verovatno teško zamisliti bilo kakvo stvarno samopoštovanje. ${ }^{61}$ Kao da se u ovim formulacijama želi istaći neodstupanje sa nekog od stanovišta, kao bitna identitetska karakteristika religijskih zajednica. Uz apsolutnost bilo kog principa, pa tako i religijskog, zaista je teško kreirati mogućnosti za toleranciju, naročito ako bi ona bila aktivnog tipa, to jest ona koja bi u sebe uključivala i dijalošku komunikaciju. ${ }^{62}$ Međureligijska tolerancija koja bi, na primer, podrazumevala raspravu o najbitnijim određenjima i osnovama same vere, međutim, nije jedini oblik religijske tolerancije na koji se može računati. Upoređujući religijsku sa političkom tolerancijom, Babić smatra da politička tolerancija predstavlja „,realno proširenje slobode ljudskog odlučivanja i povlači poštovanje potreba i dostojanstva stvarnih (sadašnjih i budućih) ljudi“"63. Pored toga, razlike se prema konceptu političke tolerancije ,tretiraju kao dopustive i dopuštene, uz isključenje nametanja vlastitog pogleda na svet kao jedino valjanog i obavezujućeg“"64.

Kada je reč o pojačanoj spremnosti za posedovanjem ispravnih interpretacija stvarnosti, kao i poštovanju dostojanstva ljudi, možemo reći da zastupnici bilo kakvih shvatanja, ukoliko ih zastupaju sa pretenzijom na ispravnost, ma koliko bili trpeljivi prema alternativnim shvatanjima, ne mogu svoja vlastita tretirati kao doslovno podjednako vredna u odnosu na ostala. ${ }^{65}$ Jer za bilo koji par alternativnih shvatanja važi, iz logičkih razloga, da ne mogu oba biti istinita. Dakle „ne može se bilo kakvo shvatanje zastupati kategorički kao ispravno i ujedno smatrati da se možda nije u pravu“"66. Kod religijskih shvatanja, radi se o još težoj problematici, jer je sa njima povezan pun egzistencijalni

61 Ibid., str. 93-94.

62 Da religijske zajednice odašilju i poruke tolerantne prirode, može se videti u njihovim štampanim glasilima, u kojima je jedan od oblika religijske tolerancije određen porukama čisto religijske prirode, u kojima se neke od tema: samousavršavanje pojedinca, o odnosu pobede i poraza, saradnje i sukoba, ljubavi i mržnje, zatim o praštanju, o otvorenosti za druge, ljubavi i strahu, toleranciji i dijalogu. O ovoj temi više u: Vasić S., Društveno-politička determinisanost oblika religijske tolerancije - analiza sadržaja religijske štampe $u$ Vojvodini, master rad, Filozofski fakultet, Univerzitet u Novom Sadu, Novi Sad 2010.

63 Ibid., str. 94.

64 Babić J., Religious and political toleration in the age of globalization, Filozofski godišnjak br. 15, Beograd 2002, str. 94.

65 Jakovljević D., Verske razlike i tolerancija, Sociološki pregled br. 4, Beograd 2007 , str. 528 .

66 Ibid., str. 528. 


\section{SLOBODAN VASIĆ}

ulog. „Trpeljivi vernik dakle mora ostati intimno ubeđen u jasnu i nesumnjivu prednost svojih vlastitih religijskih shvatanja“ u odnosu na druge, ,kojima može priznati samo u principu jednakovažnost, odnosno načelnu ravnopravnost u smislu jednakog prava na zastupanje od strane pripadnika drugih veroispovesti“ ${ }^{67}$ Zbog toga je prilikom razmatranja religijske tolerancije, važno napraviti distinkciju između podjednakog vrednovanja religijskih shvatanja i podjednakog vrednovanja pojedinaca, religijskih zajednica i konfesionalnih grupa. „Tu konsekventno trpeljivi vernik može sasvim dopustiti da personalni integritet vernika drugih konfesija i njihova prava budu doslovno podjednako vredni, kao i njihov vlastiti." 68

Što se tiče problema nametanja pogleda na svet, smatramo da se, u osnovi, vera ne može nametati, jer ne može nikakva sila da ubedi čoveka da promeni svoja vlastita verska ubeđenja. Ukoliko bi takav cilj ipak bio deo određene društveno-političke strategije, ispunjavanje takve namere bilo bi nespojivo sa vrednosnih stanovišta demokratije i pluralizma, u kojoj različite konfesionalne zajednice deluju u okviru istog društva. S druge strane, ukoliko se pod tim podrazumeva ne toliko promena postojećih verskih ubeđenja - tako što bi se prihvatala neka druga, alternativna, koliko na preobraćenje nereligioznih ljudi, postavlja se pitanje zbog čega bi ovakvu temu trebalo predstaviti kao jedini modalitet dijaloga i tolerancije između verujućih ljudi i ateista ili eventualno agnostika? Zbog toga bi bilo društveno korisno proširiti opseg njihove moguće interakcije.

\section{Zaključak}

Sadržaji hrišćanskih svetih spisa sadrže ambivalentne stavove o toleranciji, zato je u proučavanju religijske tolerancije bitno posmatrati kojim od datih formulacija, religijske zajednice pridaju veći značaj, kakve vrste poruka se šalju vernicima, ali i drugim članovima društva. Međutim, religijska tolerancija determinisana je društveno-istorijskim kontekstom. U tom smislu ona zavisi od kulturno-političke tradicije, društveno-ekonomskih odnosa posmatranog društva, te politike religijskih zajednica prema pripadnicima drugih konfesija. U skladu sa promenama tih parametara, menjaće se i oblici tolerancije ili netolerancije i načini njihovog ispoljavanja.

Visoki značaj koji ima religijska tolerancija, ne potiče toliko od činjenice što ona ima brze i merljive efekte, koliko otuda što se ona izgrađuje samosvešću i odgovornošću, otkrivajući nove prostore ljudske slobode. Smanjenje brojnih predrasuda koje

67 Ibid., str. 528.

68 Ibid., str. 528. 


\section{SLOBODAN VASIĆ}

imamo jedni o drugima, razotkrivanje korena vlastitih ubeđenja i verovanja, razobličavanje ideoloških motiva, te usvajanje stava da shvatanja drugog možemo da prihvatimo kao jednako lična, duboka i autentična - to bi bili najvažniji doprinosi religijske

tolerancije našem društvu.

\section{LITERATURA:}

Babić J., Religious and political toleration, Filozofski godišnjak br. 15, Beograd 2002.

Bigović R., Pravoslavlje i verska tolerancija, Kultura br. 91-92, Beo$\operatorname{grad} 1993$.

Jakovljević D., Monoteizam i (ne)tolerancija, Teme br. 1-2, Niš 2005.

Jakovljević D., Verske razlike i tolerancija, Sociološki pregled br. 4, Beograd 2007.

Jerotić V., Duhovnost i tolerancija, Kultura br. 91/92, Beograd 1993.

Marković M., Paternalizam i kritika: odgovor Aleksandru Prnjatu, Filozofija i društvo br. 1, Beograd 2009.

Marković M., Sloboda i praksa, Beograd 1997.

Prnjat A., Crkva i paternalizam - odgovor Mihailu Markoviću, Filozofija i društvo br. 2, Beograd 2008.

Prnjat A., Koncept religijske tolerancije, Književnost br. 10, Beograd 1999.

Prnjat A., O jezičko-ekspresivnom paternalizmu: replika Mihailu Markoviću, Filozofija i društvo br. 3, Beograd 2009.

Prnjat A., Zapis o crkvi, Književnost br. 7-9, Beograd 2000.

Šušnjić Đ., Dijalog i tolerancija, Beograd 1997.

Šušnjić Đ., Religija tom I, II, Beograd 1994.

Vasić S., Teorijski pristupi religijskoj toleranciji, Kultura br. 129, Beograd 2010.

Vasić S., Društveno-politička determinisanost oblika religijske tolerancije, master rad, Filozofski fakultet, Univerzitet u Novom Sadu, Novi Sad 2010. 


\title{
SLOBODAN VASIĆ
}

\section{Slobodan Vasić \\ University of Novi Sad, Association of Centres for Interdisciplinary and Multidisciplinary Studies and Developmental Research) ACIMSI \\ CONTEMPLATION OF THE RELIGIOUS TOLERANCE IN CONTEMPORARY SERBIAN AND SOCIAL THOUGHT}

\begin{abstract}
Following the dissolution of the SFRY, and in the light of new social circumstances, the religious communities have new social status and new social role; they have come out from the private sphere and found its place in the public one. Religious tolerance is more significant in the context of desecularization of social life, both for the religious communities themselves, and for other social actors and the society as a whole. With this in mind, the goal of this paper is to analyse theoretical views and definitions of the notion of religious tolerance in the papers of domestic authors-philosophers, representatives of social sciences as well as theologians. In addition to the analysis of the impact of social context, the relation between monotheism and in/tolerance is also analysed, whereas a doctrinaire aspect, i.e. the content of the sacred texts, is contemplated as well. A consideration is given to the possible subjects of the religious tolerance, and a problem of paternalism is pointed out in the speeches on religion stressing the importance of the mutual appreciation and respect among the actors of the dialogue communication. In accordance with the current views on im/possibility of the tolerance among different denominations, that is, religions, due to their different standpoints on the man's path to salvation, emphasize is given to the difference between valuing cognition and valuing an actor-individuals, communities and social groups.
\end{abstract}

Key words: religious tolerance, social context, sacred texts, paternalism, monotheism, doctrine 